\title{
GESTÃO PÚBLICA ESCOLAR E O ESTRESSE OCUPACIONAL NO CONTEXTO DA PANDEMIA DA COVID-19 EM CEILÂNDIA-DF
}

\author{
School public management and occupational stress in \\ COVID-19 pandemic context in Ceilândia-DF
}

Giovana Alves de Souza Araujo ${ }^{1}$

\begin{abstract}
Resumo: Este trabalho teve como objetivo identificar o estresse ocupacional advindo da pandemia da COVID-19 em diretores e vice-diretores de escolas públicas de ensino médio da Região Administrativa de Ceilândia, no Distrito Federal. Os objetivos específicos são identificar: as demandas ocupacionais desses gestores; os principais causadores de estresse enfrentados por esses gestores; e como as atividades de gestão pública escolar foram impactadas com o surgimento da pandemia da COVID-19. Devido à necessidade de distanciamento social, a coleta de dados foi por meio da aplicação de questionário, com abordagem qualitativa, baseado no Modelo Teórico de Explicação do Estresse Ocupacional em Gerentes, desenvolvido por Zille (2005), com questões adaptadas. A análise apresenta a percepção dos gestores sobre a intensificação do trabalho no contexto de pandemia da COVID-19. Foram identificados como principais fatores relacionados ao estresse: a articulação da Secretaria de Educação; o excesso de demandas; e a utilização e acesso a tecnologias por toda a comunidade escolar. Os resultados e discussões poderão servir de base para políticas públicas sobre o tema.
\end{abstract}

Palavras-chave: Gestão Escolar, Estresse, COVID-19.

\begin{abstract}
This work aimed to identify the occupational stress arising from the COVID19 pandemic in principals and deputy directors of public high schools in the Administrative Region of Ceilândia, in the Federal District. The specific objectives are to identify: the occupational demands of these managers; the main stressors faced by these managers; and how school public management activities were impacted by the emergence of the COVID-19 pandemic. Due to the need for social distance, data collection was carried out through the application of a questionnaire, with a qualitative approach, based on the Theoretical Model for Explanation of Occupational Stress in Managers, developed by Zille (2005), with adapted questions. The analysis presents the managers' perception about the intensification of work in the context of the COVID-19 pandemic. The main factors related to stress were identified: the articulation of the Education Department; excess demands; and the use and access to technologies by the entire school community. The results and discussions may serve as a basis for public policies on the subject.
\end{abstract}

Key-words: School Management, Stress, COVID-19.

\footnotetext{
${ }^{1}$ Graduanda em Gestão Pública pelo Instituto Federal de Educação, Ciência e Tecnologia de Brasília (IFB) e em Pedagogia pela Universidade Estácio de Sá. Professora Assistente na Maple Bear Canadian School. Coordenadora de voluntários do grupo de ações sociais RealizAção. Ex-monitora e Ledora no Núcleo de Apoio a Pessoas com Necessidades Específicas (NAPNE), no IFB. Excoordenadora de comunicação do Diretório Central dos Estudantes do Centro Universitário de Brasília (Uniceub) - Campus Taguatinga.
} 


\section{Introdução}

A gestão de escolas públicas tem se mostrado, no contexto da administração, um trabalho complexo, pois deve ser capaz de conciliar de forma equilibrada os aspectos burocráticos e os aspectos dinâmicos, próprios desse tipo de organização. A articulação desta capacidade conciliatória requer do gestor mais energia e sagacidade nas ações laborais, situação que pode intensificar o desgaste físico e mental, e gerar patologias ligadas ao estresse.

Segundo o SindSaúde-DF, a partir de dados fornecidos pela Diretoria de Epidemiologia em Saúde do Servidor, das licenças para afastamento emitidas aos servidores do DF em 2017, mais de $22 \%$ foram por motivos de transtornos mentais ou comportamentais, totalizando 15.557 atestados para tratar dessas enfermidades. As Secretarias recordes na emissão desses afastamentos foram a de Educação (28,34\%), seguida pela de Saúde (19\%).

No caso dos profissionais em educação, em especial dos gestores escolares de escolas públicas, há possibilidade do estresse estar ligado a fatores presentes no cotidiano operacional da instituição como: demanda dos órgãos superiores; atendimento à comunidade escolar (professores, pais, alunos); e sobrecarga da jornada, que podem se estender ao ambiente familiar e se configurar como consequências diretas do estresse no desempenho da função.

Em dezembro de 2019, foi identificada em Wuhan, na China, a transmissão de um novo vírus (SARS-CoV-2), o qual causou a COVID-19, que foi disseminada e transmitida mundialmente de pessoa para pessoa. A COVID-19 é uma doença que apresenta quadros clínicos que podem variar entre infecções assintomáticas, um resfriado, uma Síndrome Gripal-SG (presença de um quadro respiratório agudo) e até a uma pneumonia severa. As primeiras confirmações oficiais de transmissão comunitária ocorreram em março de 2020. E, a partir daí, medidas de isolamento e distanciamento social começaram a ser tomadas no Distrito Federal, dentre elas o fechamento de instituições de ensino públicas e privadas.

A partir do conteúdo exposto, busca-se identificar se as demandas do trabalho de gestão escolar pública em contexto de pandemia intensificaram o estresse e o desempenho da função. Assim, surgiu a seguinte pergunta de pesquisa: as demandas advindas da pandemia da COVID-19 intensificaram o estresse ocupacional de diretores e vice-diretores de escolas públicas de ensino médio da Região Administrativa de Ceilândia, no Distrito Federal? Os objetivos específicos são identificar: 1) as demandas ocupacionais dos gestores das escolas públicas de ensino médio da Ceilândia, no Distrito Federal; 2) os principais causadores de estresse enfrentados por esses gestores; e 3) como as atividades de gestão pública escolar foram impactadas com o surgimento da pandemia da COVID-19. Diante desse contexto, justifica-se a necessidade de um estudo mais aprofundado sobre os fatores de incidência do estresse entre os gestores educacionais de instituições públicas.

Devido à carência de estudos sobre o tema apresentado, os resultados desse trabalho podem fundamentar políticas públicas relacionadas aos processos de formação profissional dos gestores e a ampliação das relações de parceria entre as Secretarias de Educação, de Saúde e demais segmentos sociais que tenham condições de contribuir para a minimização das circunstâncias causadoras do adoecimento desta categoria.

Rev. Nova Paideia - Revista Interdisciplinar em Educação e Pesquisa Brasília/DF, v. 2, n. 2. p. 39 - 55 - $\overline{\text { ANO } 2020}$ 


\section{Revisão de literatura}

Nesta seção quatro aspectos serão abordados para fundamentar o estudo. São eles: a gestão escolar; a gestão escolar nas escolas públicas; o estresse no desempenho da função; e o estresse no desempenho da função diante do contexto de pandemia.

\subsection{A gestão escolar}

Entre as décadas de 1930 e 1980, os processos de gerenciamento escolar estavam enraizados nos princípios da Administração Clássica. Nesse modelo, os diretores assumiram a função de administradores escolares. Libâneo (1997) apresenta o conceito de "Administração Escolar" como o estudo das questões relacionadas com planejamento, organização, gestão e controle de atividades educacionais, com base na racionalização e em métodos de trabalho, sustentado por relações hierárquicas e normas.

Os documentos de reformas educacionais produzidos ao final da década de 1980 e durante os anos 1990 sinalizam para a necessidade de ampliação do conceito da administração tradicional no espaço escolar.

O termo gestão ganha mais abrangência que administração e organização porque é proposto dentro de uma visão sistêmica, que concebe o sistema de ensino como um todo: políticas e diretrizes educacionais às escolas, gestão de sistemas de ensino e escolas, autonomia, processos participativos. (LIBÂNEO, 1997, p. 15)

O artigo 206 da Constituição Federal de 1988 define a gestão democrática como princípio do ensino público em forma de Lei, enquanto a Lei de Diretrizes de Bases da Educação Nacional de 1996 expressa, no artigo 14, que a participação dos profissionais da escola e da comunidade escolar são princípios fundamentais da gestão democrática. Nesse contexto, o conceito de gestão educacional ou gestão escolar se fundamenta como

\footnotetext{
0 processo de gerir a dinâmica do ensino como um todo e de coordenação das escolas em específico, afinado com as diretrizes e políticas educacionais públicas para a implementação das políticas públicas educacionais e projetos da escola, compromissados com os princípios da democracia e com os métodos que organizem e criem condições para a organização de um ambiente educacional autônomo, de participação e compartilhamento, autocontrole e transparência. (LUCK, 2017, p. 21)
}

Segundo Machado et al. (2014), os gestores precisam conciliar, no dia a dia, a gestão estratégica e operacional da escola, o que acaba por estabelecer uma dinâmica de trabalho conturbada e intensa. O processo de Gestão Estratégica inclui "diferentes níveis, processo cognitivo dos tomadores de decisão, processos sociais e psicológicos e, ainda, regras e rotinas organizacionais que orientam e condicionam decisões e ações". (CHAKRAVARTHY; WHITE, 2006, apud MEYER; PASCUCCI; MANGOLIN, 2012, p. 51). Já a Gestão Operacional, "um espaço integrador das competências que um gestor público

Rev. Nova Paideia - Revista Interdisciplinar em Educação e Pesquisa Brasília/DF, v. 2, n. 2. p. 39 - 55 - $\overline{\text { ANO } 2020}$ 
deve possuir para exercer uma efetiva gestão da prestação de serviços públicos, por um órgão do Estado ou mesmo por uma entidade não estatal". (MALMEGRIN, 2014, p. 12).

\title{
2.2 A gestão escolar nas escolas públicas
}

A forma de provimento dos cargos de diretor e vice-diretor das escolas públicas do Distrito Federal é embasada conforme o disposto na Lei Distrital no 4.751/2012 e a Resolução $\mathrm{N}^{\circ} 1$, de 27 de setembro de 2019, da Secretaria de Estado de Educação do Distrito Federal. Conforme as referidas legislações, o processo eleitoral envolve toda a comunidade escolar, como: professores, auxiliares de educação, pais e estudantes. Desde a promulgação da Lei foram realizadas cinco eleições: em 2012, 2013, 2015, 2017 e 2019. Contudo, algumas escolas podem não ter candidatos interessados em participar do pleito. Nessas situações é feita uma indicação pela Secretaria de Educação, que convocará novas eleições em até 180 dias. Caso não haja candidatos novamente, os indicados permanecerão até o fim do mandato. Conhecidos os diretores eleitos, a Secretaria de Educação do Distrito Federal promove curso de formação inicial visando à qualificação para o exercício da função, que inclui administração em recursos humanos, políticas pedagógicas, patrimoniais, financeiras e prestação de serviços, dentre outras.

A instituição educacional é um espaço de discussão e debate onde todos os agentes envolvidos, estudantes, professores, família, equipe gestora e de suporte educacional interagem no processo da tomada de decisões, orientando-se pelos anseios e objetivos da comunidade escolar. 0 Governo do Distrito Federal apresenta essa ideia por meio do site oficial da Secretaria de Estado de Educação:

\begin{abstract}
A Secretaria de Estado de Educação do Distrito Federal (SEEDF) promove estratégias para ressignificar o Ensino Médio distrital. Dentre as ações empreendidas, estão a implementação da organização pedagógica em semestres e o estímulo à efetiva participação da comunidade escolar em debates voltados à identificação das necessidades de aprimoramento na estrutura educacional, com vistas à garantia dos direitos de aprendizagem. (DISTRITO FEDERAL, 2020).
\end{abstract}

Contudo, essa percepção de espaço aberto pode recair sobre o gestor na execução das atividades diárias. Mesmo que haja equipe de suporte, o agente central de operacionalização desta expectativa da comunidade local ainda é o diretor da instituição escolar. Palmen (2014) apresenta seu pensamento sobre o tema da seguinte forma:

Dentre suas responsabilidades inserem-se demandas de ordem organizacional que fazem parte do papel burocrático que exercem, sendo-lhes atribuída a função de zelar pelo pedagógico, mas também pelo cumprimento das demandas legais presentes no sistema educacional, pelas questões administrativas que vão além do domínio dos procedimentos organizacionais e cadastrais de pessoal e criança matriculadas, englobando a gestão patrimonial e a manutenção das instalações escolares. (PALMEN, 2014, p.162).

\subsection{0 estresse no desempenho da função}


Originária do inglês stress, a palavra estresse tem o seu significado ligado às palavras tensão, insistência ou pressão. Uma das definições admissíveis, construída a partir de uma dimensão biológica, segundo Selye (1959), fundamenta-se em um conjunto de reações fisiológicas necessárias à adaptação a novas situações e que produzem alterações na estrutura e composição química do corpo, podendo ser avaliadas a partir dos relatos dos indivíduos. Couto, Vieira e Lima (2007, p. 113) afirmam que o estresse "caracteriza-se por desgaste anormal e/ou redução da capacidade de trabalho, ocasionado basicamente por uma desproporção prolongada entre o grau de tensão a que o indivíduo está exposto e a capacidade de suportá-lo". Reis et al. (2010) salientam que a perspectiva clínica tem estudado o estresse como um evento psicofisiológico a partir da percepção individual de disfunções entre as demandas ambientais e a capacidade de resposta da pessoa.

Apreende-se da obra de Paro (2010) que os diretores escolares enfrentam contradições entre os objetivos educacionais da escola e as demandas administrativas. Essas demandas devem estar de acordo com as orientações do sistema de ensino, que são bastante burocráticas e exigem bastante tempo de trabalho do diretor. Essas atribuições podem ultrapassar os limites do cotidiano do ambiente escolar, indo até o âmbito pessoal, além de exposição a situações diversas, envolvendo toda a comunidade escolar com diferentes reivindicações.

Vale citar o pensamento de Carlotto e Silva (2003) sobre a temática de fatores estressores na gestão escolar:

\begin{abstract}
As constantes mudanças ocorridas no sistema público de educação não raras vezes geram nesses profissionais sentimentos de mal-estar e impotência. 0 trabalho geralmente é realizado sob alguns fatores potencialmente estressores como: baixos salários, escassos recursos materiais e didáticos, classes superlotadas, tensão na relação com alunos, excesso de carga horária, inexpressiva participação nas políticas e no planejamento institucional e falta de segurança no contexto escolar. (CARLOTTO; SILVA, 2003, p. 1).
\end{abstract}

Pesquisa realizada Vieira (2007) pela Confederação Nacional dos Trabalhadores em Educação, que abrange instituições de ensino públicas e privadas, municipais e estaduais, apresenta dados sobre licenças para atendimento à saúde. 0 estudo demonstra que há uma tendência que revela o peso das doenças mentais e/ou emocionais sobre a saúde dos (as) trabalhadores (as) em educação entre os anos de 2012 e 2016:

As licenças foram motivadas por cirurgia, depressão e estresse, seguidas de muitas outras necessidades de afastamento do trabalho[...]. Observe-se que o estresse e a depressão figuram entre as doenças mais citadas pelo conjunto dos (as) profissionais da educação. (VIEIRA, 2017, p. 87).

\title{
2.4 0 estresse no desempenho da função diante do contexto de pandemia
}

Como medida preventiva ao crescente número de casos de contaminação pela COVID-19 em escala mundial, o Governo do Distrito Federal adotou uma política de isolamento social marcado inicialmente pelo fechamento das escolas públicas e particulares através do decreto n⿳0 40.520, de 14 de março de 2020, que dispõe que: 
III - atividades educacionais em todas as escolas, universidades e faculdades, das redes de ensino pública e privada;

$\S 1^{\text {o }}$ A suspensão das aulas na rede de ensino pública do Distrito Federal, de que trata o inciso III, deverá ser compreendida como recesso/férias escolares do mês de julho e terá início a partir do dia 16 de março de 2020, nos termos deste Decreto.

§ 2o 0 recesso/férias escolares terá duração máxima de 15 dias corridos, independente do quantitativo de dias de recesso constante no calendário escolar da unidade de ensino.

$\S 3^{\text {o }}$ As unidades escolares da rede privada de ensino do Distrito Federal poderão adotar a antecipação do recesso/férias prevista neste Decreto, ou determinar a suspensão das aulas pelo período determinado, a critério de cada unidade.

$\S 4^{\circ}$ Os ajustes necessários para o cumprimento do calendário escolar serão estabelecidos pela Secretaria de Estado de Educação do Distrito Federal, após o retorno das aulas. (DISTRITO FEDERAL, 2020)

As atividades escolares ficaram suspensas de forma integral durante os meses de março a junho para estudantes, professores e auxiliares em educação. Para os gestores escolares e Chefes de Secretaria, as atividades laborais passaram a ser alternadas entre o exercício remoto e o presencial para o atendimento das demandas de cunho administrativo, social e logístico necessárias no ambiente escolar e na comunidade.

Art. 12 As atividades não presenciais a serem desempenhadas em regime de teletrabalho pelos servidores se darão [...]: Equipe Gestora [...] Escala de revezamento presencial na unidade escolar em cumprimento das atribuições regimentais. Quando não estiver presencialmente na escola deverá estar em teletrabalho. (DISTRITO FEDERAL, 2020)

Foram acrescidas à rotina de trabalho presencial dos gestores escolares demandas como remanejamento de alimentos perecíveis para instituições de serviço social, distribuição de cestas básicas e cestas verdes à comunidade escolar em situação de vulnerabilidade, reformas e desinfecções periódicas das escolas.

As etapas de retorno às atividades escolares não presenciais foram instituídas pela portaria no133 da Secretaria de Estado de Educação do Distrito Federal de 05 de junho de 2020.

Art. $3^{\circ}$ As atividades educacionais não presenciais acontecerão de forma gradativa e conforme as seguintes fases:

I - Fase 1: acolhimento e formação dos profissionais da educação, e planejamento e produção das atividades não presenciais;

II - Fase 2: levantamento sobre turmas/estudantes, modulação de pessoal (se necessário), produção de atividades não presenciais e formação continuada dos profissionais da educação;

III - Fase 3: retorno dos estudantes de forma não presencial, produção de atividades não presenciais e formação continuada dos profissionais da educação. (DISTRITO FEDERAL, 2020).

No trabalho remoto, as etapas de preparação, organização, estruturação e inserção de professores e estudantes na plataforma digital exigiram dos diretores e 
supervisores pedagógicos a administração do tempo de trabalho. A administração do tempo também foi necessária nas ações de aprendizagem do uso da plataforma, de aplicação e de construção de uma escola virtual semelhante à escola real para o atendimento de estudantes, professores e demais partícipes da comunidade escolar. As reuniões presenciais foram substituídas por reuniões online e atividades de formação virtual.

Art. 23 É responsabilidade da equipe gestora das unidades escolares:
I - planejar, coordenar e controlar a execução do Plano de Gestão Estratégica
para a Realização das Atividades Pedagógicas Não Presenciais no Distrito
Federal no âmbito da UE/UEE/ENE, em se tratando da Educação Profissional,
do Plano Estratégico de Retomada das Atividades Pedagógicas Não Presenciais
da Educação Profissional;
II - monitorar o desempenho dos servidores no Plano de Gestão Estratégica
para a Realização das Atividades Pedagógicas Não Presenciais no Distrito
Federal e, em se tratando da Educação Profissional, do Plano Estratégico de
Retomada das Atividades Pedagógicas Não Presenciais da Educação
Profissional;
III - fornecer, sempre que demandados, dados e informações sobre o
andamento do Plano de Gestão Estratégica para a Realização das Atividades
Pedagógicas Não Presenciais no Distrito Federal na sua UE/UEE/ENE e, em se
tratando da Educação Profissional, do Plano Estratégico de Retomada das
Atividades Pedagógicas Não Presenciais da Educação Profissional;
IV - planejar, coordenar e controlar a execução de AVA e outras ferramentas
digitais, quando for o caso;
V - manter atualizadas as turmas no sistema i-Educar e AVA. (DISTRITO
FEDERAL, 2020)

Os meses de junho e julho foram direcionados ao processo de busca ativa estudantil, que consiste no atendimento e esclarecimento à comunidade escolar sobre os processos de retorno e permanência dos estudantes às atividades pedagógicas remotas, tanto nas redes sociais quanto no contato presencial com as famílias sem acesso aos meios digitais.

Para os estudantes sem acesso à plataforma digital, a gestão escolar necessita articular estratégias logísticas de reprodução, entrega e coleta das atividades impressas. Mesmo com o retorno dos estudantes às atividades remotas, as estratégias de busca ativa foram estendidas a todo o período de execução de atividades não presenciais, devido ao quantitativo discente que ainda não participa das atividades escolares, sejam elas via plataforma ou via impressa.

O contexto da pandemia e, proporcionalmente, o volume das ações específicas para este período apresentam indícios de intensificação das atividades exercidas pelos gestores escolares. Apontamentos relevantes que fundamentam os objetivos de realização deste trabalho.

Até o mês de outubro de 2020, as aulas ainda não haviam retornado nas escolas públicas do Distrito Federal. A Organização para a Cooperação e Desenvolvimento Econômico (OCDE) publicou, nesse mesmo mês, o documento Education at a Glance 2020. Este documento é uma fonte confiável de informações sobre o estado da educação em todo o mundo, e afirma que essa reabertura das escolas no contexto da pandemia depende da capacidade de manter uma distância segura de 1 a 2 metros entre alunos e

Rev. Nova Paideia - Revista Interdisciplinar em Educação e Pesquisa Brasília/DF, v. 2, n. 2. p. 39 - 55 - $\overline{\text { ANO } 2020}$ 
funcionários. Afirma ainda que "reduzir o tamanho das turmas pode depender de outros fatores, como espaço físico, disponibilidade de salas e funcionários e decisões pessoais dos alunos e funcionários sobre o retorno à escola". (OCDE, 2020, p. 6-7).

Além disso, no ensino médio, a razão aluno-professor do Brasil é uma das maiores entre os países da OCDE e os parceiros, a média dos países é 13 alunos por professor, enquanto no Brasil é 24. 0 que dificulta ainda mais o retorno das aulas presenciais em comparação com outras nações.

\section{Metodologia}

Na presente seção, apresentam-se os elementos metodológicos que orientam este trabalho, considerando a caracterização da pesquisa, a população ou amostra, o instrumento de coleta de dados e a coleta e análise de dados.

\subsection{Caracterização de pesquisa}

Para a realização desta pesquisa, foi utilizada a abordagem qualitativa que Creswell (2010, p. 43) define como "um meio para explorar e para entender o significado que os indivíduos ou os grupos atribuem a um problema social ou humano". 0 autor afirma ainda sobre essa abordagem que:

\footnotetext{
o investigador sempre faz alegações de conhecimento com base principalmente ou em perspectivas construtivistas (ou seja, significados múltiplos das experiências individuais, significados social e historicamente construídos, com o objetivo de desenvolver uma teoria ou um padrão). [...] 0 pesquisador coleta dados emergentes abertos com o objetivo principal de desenvolver temas a partir dos dados. (CRESWELL, 2010, p. 35).
}

A pesquisa busca fazer uma análise descritiva, que, segundo Vergara (2000, p. 47), "expõe características de determinada população ou determinado fenômeno. Pode também estabelecer correlações entre variáveis e definir sua natureza”.

A partir disso, busca-se identificar, interpretar e analisar os fatores estressores intensificados ou emergentes devido às novas condições de trabalho provocadas pela pandemia da COVID-19 de acordo com a percepção de gestores escolares.

\subsection{Corpus da pesquisa}

Como objeto de análise dessa pesquisa foram escolhidos diretores e vicediretores das escolas públicas de ensino médio da Região Administrativa de Ceilândia, no Distrito Federal (Tabela 1). Dos 26 gestores eleitos em 2019, conforme o disposto na Lei Distrital no 4.751/2012, participaram voluntariamente da pesquisa 5 diretores e 6 vice-diretores, totalizando 11 respostas. A amostra foi selecionada de forma intencional, ou seja, foram escolhidos indivíduos que de fato vivem a realidade a ser pesquisada e podem contribuir significativamente para os resultados. 
Tabela 1 - Identificação das escolas de Ensino Médio da Região Administrativa de Ceilândia

\begin{tabular}{lccc}
\hline ESCOLA & No DE ALUNOS & DIRETOR & VICE-DIRETOR \\
\hline CED 06 & 1.181 & Jefferson Reges Lobato & Ricardo Jardim de Medeiros \\
CED 07 & 1.216 & Adriana de Barros R. Sousa & Cristiane Alves Araujo \\
CED 11 & 581 & Francisco Gadelha Araújo Martins & Micheline Lara de Oliveira \\
CED 14 & 560 & Frederico dos Santos Viana & Carlos Alberto Almeida da Silva \\
CED 15 & 1.288 & Anderson Pereira de Souza & Cleber Oliveira Vargas \\
CED 16 & Não informado & Wellington Germano de Queiroz & Ana Paula Barbosa de Brito \\
CED Incra 09 & 105 & Márcio Régis Moura de Oliveira & Cláudio Roberto Ferreira Rodrigues \\
CEM 02 & 1.982 & Eliel de Aquino & Halbert Alessandro Orem da Cruz \\
CEM 03 & 940 & Divaldo de Oliveira & Fernando Lourenço da Silva \\
CEM 04 & 1.452 & Nilson Couto Magalhães & Washington Luiz dos Santos Carvalho \\
CEM 09 & 1.180 & José Gadelha Loureiro & Maria José Ferreira dos Pessoa \\
CEM 10 & 740 & Helen Matsunaga & Conrado de Souza Ferreira \\
CEM 12 & 1.600 & Mirtes Correia de Jesus & Daniela de Barcelos Vieira Lima \\
\hline
\end{tabular}

\subsection{Instrumento de coleta de dados}

Para a coleta de dados, foi escolhida a aplicação de um questionário online, enviado aos diretores e vice-diretores por e-mail e respondido remotamente pela plataforma Formulários Google. As perguntas realizadas no questionário foram baseadas na entrevista "Pandemia: desafios para a escola e seus gestores", de Tognetta e Menin (2020), e nas parte B e C do Modelo Teórico de Explicação do Estresse Ocupacional em Gerentes (MTEG), criado por Zille (2005), na pesquisa sobre "novas perspectivas para abordagem do estresse ocupacional em gerentes - estudo em organizações brasileiras de setores diversos".

0 questionário possuía 16 questões divididas em 3 seções, foram elas: 1) Identificação demográfica; 2) Percepções, sintomas e desafios; e 3) Pontos de vista dos entrevistados. Na primeira seção, foram abordados aspectos pessoais e relacionados ao tempo de ocupação em cargo de gestão, havia 7 questões fechadas e 2 abertas. Na segunda seção, havia 4 questões fechadas do tipo caixa de seleção, nas quais os participantes selecionaram quais percepções, sintomas e desafios identificaram no contexto de pandemia em relação ao trabalho de gestão. Por fim, na terceira seção, os participantes puderam identificar por meio de 3 questões abertas outros fatores estressores que não haviam sido abordados no questionário, desafios e fatores considerados atenuantes ao estresse. 
A escolha do instrumento de coleta foi definida de acordo com as vantagens de utilizar um questionário apontadas por Marconi e Lakatos (2003), são elas:

a) Economiza tempo, viagens e obtém grande número de dados.

b) Atinge maior número de pessoas simultaneamente.

c) Abrange uma área geográfica mais ampla.

d) Economiza pessoal, tanto em adestramento quanto em trabalho de campo.

e) Obtém respostas mais rápidas e mais precisas.

f) Há maior liberdade nas respostas, em razão do anonimato.

g) Há mais segurança, pelo fato de as respostas não serem identificadas.

h) Há menos risco de distorção, pela não influência do pesquisador.

i) Há mais tempo para responder e em hora mais favorável.

j) Há mais uniformidade na avaliação, em virtude da natureza impessoal do instrumento.

I) Obtém respostas que materialmente seriam inacessíveis. (MARCONI; LAKATOS, 2003, p. 201- 202).

Para aumentar a eficácia do resultado da pesquisa, foi realizado um pré-teste com uma vice-diretora escolar, escolhida por se adequar ao perfil dos futuros entrevistados. 0 pré-teste foi aplicado a fim de conferir se o questionário apresentava clareza, equivalência semântica e objetividade em seu conteúdo, e suas respostas não foram contabilizadas na fase de análise. Além disso, Marconi e Lakatos (2003) afirmam que

0 pré-teste serve também para verificar se o questionário apresenta três importantes elementos:

a) Fidedignidade. Qualquer pessoa que o aplique obterá sempre os mesmos resultados.

b) Validade. Os dados recolhidos são necessários à pesquisa.

c) Operatividade. Vocabulário acessível e significado claro. (MARCONI; LAKATOS, 2003, p. 203).

Com a aplicação do teste, foi possível suprimir questões repetitivas, alterar as que poderiam causar dupla interpretação e calcular o tempo médio de resposta do instrumento.

Além disso, o questionário apresentava em sua página inicial informações sobre a temática da pesquisa, o público alvo, o sigilo dos dados sensíveis, o tempo médio de respostas e a finalidade do estudo, de forma que o gestor obtivesse ciência do que dele era desejado.

\subsection{Coleta e Análise dos dados}

Para Marconi e Lakatos (2006, p. 166), a coleta de dados é a "etapa da pesquisa em que se inicia a aplicação dos instrumentos elaborados e das técnicas selecionadas, a fim de se efetuar a coleta dos dados previstos". As autoras elucidam ainda que "são vários os procedimentos para a realização da coleta de dados, que variam de acordo com as circunstâncias ou com o tipo de investigação".

Para coletar as informações necessárias, realizou-se levantamento de dados no formato de questionários online estruturados. Devido à epidemia do coronavírus e às regras de isolamento e distanciamento social, a aplicação dos questionários ocorreu de 
forma não presencial e a coleta de dados foi realizada mediante envio do instrumento por e-mail contendo o link do formulário.

Para a análise dos dados, foi utilizada a análise de conteúdo, que possibilita um processamento adequado dos dados qualitativos. As informações foram divididas e organizadas em três fases definidas por Bardin (1977): 1) pré-análise; 2) exploração do material; e 3) tratamento dos resultados, inferência e interpretação. A técnica permitiu a utilização dos questionários como importantes instrumentos de informação para responder ao problema de pesquisa e aos seus respectivos objetivos específicos. Para a análise e contagem de indicadores, foram utilizados o software Excel versão 2016 e a ferramenta online Formulários Google.

Para a pré-análise, foi retomada a pergunta de pesquisa e os objetivos específicos, a fim de nortear o que era necessário extrair e interpretar dos dados dispostos. A exploração do material se deu com a leitura das questões abertas e fechadas enviadas pelos gestores através do questionário, com isso foi possível identificar trechos, palavras e ideias comuns ou semelhantes nas respostas. A identificação dessas convergências possibilitou uma reorganização e divisão dos dados que resultou em 4 categorias de análise que serão abordadas em resultados e discussão.

\title{
3.5 Análise de conteúdo
}

Para a análise, foi realizada uma codificação que Bardin (1977) descreve como:

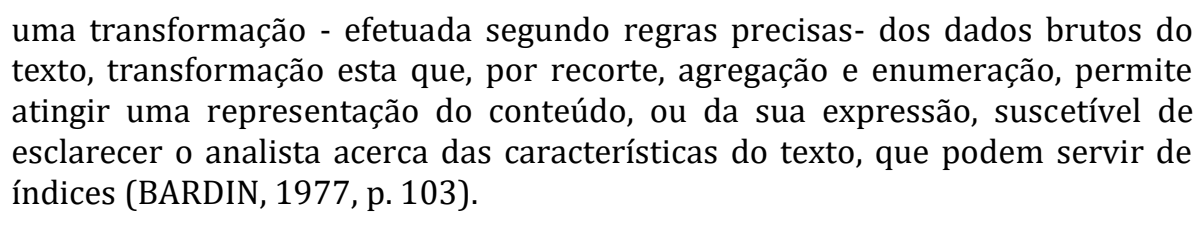

A autora define ainda dois conceitos que norteiam essa codificação, a Unidade de Registro e a Unidade de contexto:

\begin{abstract}
a) A unidade de registro - É a unidade de significação a codificar e corresponde ao segmento de conteúdo a considerar como unidade de base, visando a categorização e a contagem frequencial. [...]

b) A unidade de contexto - A unidade de contexto serve de unidade de compreensão para codificar a unidade de registo e corresponde ao segmento da mensagem, cujas dimensões (superiores às da unidade de registo) são ótimas para que se possa compreender a significação exata da unidade de registo. (BARDIN, 1977, p. 104 e 107).
\end{abstract}

Como unidade de registro foram escolhidos recortes a nível semântico, por tema. Já como unidade de contexto, utilizou-se o estresse ocupacional em diretores e vicediretores das escolas públicas de ensino médio da Região Administrativa de Ceilândia, no Distrito Federal. Foram definidas 4 categorias de análise criadas após a exploração dos dados presentes no formulário. Essas categorias foram criadas para simplificar a representação dos dados brutos e conhecer índices invisíveis, ao nível desses dados. São elas: a articulação da Secretaria de Educação; o excesso de demandas; a utilização e o acesso a tecnologias; e contrapontos apresentados por gestores sobre a pesquisa.

Rev. Nova Paideia - Revista Interdisciplinar em Educação e Pesquisa Brasília/DF, v. 2, n. 2. p. 39 - 55 - $\overline{\text { ANO } 2020}$ 


\section{Resultados e discussão}

Inicialmente, são apresentados aspectos demográficos que apresentam a descrição do perfil dos gestores pesquisados, levando em consideração as variáveis demográficas sexo, etnia e faixa etária. São apresentados ainda dados referentes aos aspectos ocupacionais como cargo, tempo na função de gestor, percepção de estresse ocupacional e ocorrências de afastamento do trabalho por questões de saúde emocional. Em um segundo momento, são apresentadas as 4 categorias de análise criadas após a exploração dos dados presentes no formulário.

\subsection{Demografia e aspectos ocupacionais}

Dos 11 gestores pesquisados, 63,6\% são do sexo feminino, sendo identificadas como maioria entre os participantes da pesquisa. $45,5 \%$ se identificaram etnicamente como brancos, $36,4 \%$ como pardos e $18,25 \%$ como negros. Para a identificação da idade dos gestores, foram definidas 5 faixas etárias. A primeira faixa é de 18 a 24 anos, e as 4 seguintes possuíam intervalos de 10 anos, sendo a última composta por gestores com 54 anos ou mais. A faixa etária de 45 a 54 anos foi a que apontou um maior número de gestores, representando $72,7 \%$ dos pesquisados, seguida da de 35 aos 44 anos, com $18,2 \%$ e por último a de mais de 54 anos, com 9,1\%.

Considerando o cargo ocupado pelos participantes, a maior parcela dos gestores é composta por vice-diretores, sendo eles 54,5\% da amostra. Desta amostra, 81,8\% dos gestores exercem a função há mais de 5 anos. Quando perguntado se exerciam uma função estressante, $81,8 \%$ responderam que sim e $18 \%$ responderam que não. No histórico de trabalho em gestão, 36\% dos participantes já precisaram afastar-se do trabalho por razões de saúde emocional.

\subsection{A articulação da Secretaria de Educação no contexto da pandemia}

Na seção de questões de múltipla escolha, pouco foi abordado sobre a atuação da Secretaria de Educação do Distrito Federal (SEEDF), porém os gestores utilizaram do recurso das questões abertas para expor opiniões e críticas sobre o órgão.

Quando questionados sobre fatores causadores de tensão excessiva, foram apontadas a existência de falhas de planejamento e de organização da SEEDF, além de constantes mudanças nas orientações sobre as estratégias de trabalho remoto e de falhas apontadas em relação ao atendimento aos alunos.

As proposições apresentadas pelos pesquisados evidenciam elementos importantes sobre a ampliação do debate entre os diferentes partícipes da administração pública, em especial da gestão educacional, na construção de normativas de ação voltadas ao espaço escolar.

\subsection{0 excesso de demandas}


$\mathrm{Na}$ quarta seção do questionário foram apresentadas percepções, sintomas e desafios identificados pelos participantes entre os meses de março e setembro de 2020 .

As percepções que mais se destacaram foram referentes à realização de mais atividades ao mesmo tempo; dificuldade de desligar-se do trabalho; e assumir compromissos muito desafiadores. É importante evidenciar as muitas avaliações voltadas a um aumento exponencial de demandas técnico-pedagógicas pelos professores, além da afirmação de que parte dos horários de descanso estava sendo tomada pelo trabalho.

Em um segundo momento, também foi solicitada a percepção em relação a aspectos intensificadores de estresse na ocupação em comparação ao mesmo período (março a setembro) do ano anterior. As percepções mais elencadas em relação a demandas foram sobre executarem um trabalho mais complexo e notarem um maior desgaste resultante disso; por sofrerem ainda mais pressão nos processos de gestão administrativos e pedagógicos; e por realizarem várias atividades ao mesmo tempo, com alto grau de cobrança.

Quando perguntados sobre sintomas, os mais apontados foram dor nos músculos do pescoço e ombros, dor de cabeça por tensão, falta ou excesso de apetite e insônia. Sinais característicos de tensão e estresse em demasia.

\subsection{Utilização e acesso a tecnologias}

Quando perguntado aos gestores sobre os maiores desafios enfrentados diante da realidade do ensino remoto, os fatores mais apontados foram em relação à tecnologia e sua utilização e acesso por toda a comunidade escolar.

As afirmativas de maior destaque em relação aos gestores estão direcionadas a uma sobrecarga laboral em relação ao uso de novas plataformas de ensino, e-mail, softwares, sistemas integrados de gestão; excesso de reuniões online e de protocolos administrativos; além do domínio das novas tecnologias. Também foram vistos como desafios a formação técnica aos professores que não possuem domínio tecnológico e a resistência de alguns professores a se adaptarem às plataformas digitais de ensino.

Em relação aos alunos, notou-se que os cadastros desatualizados dos estudantes dificultaram a comunicação e obtenção de dados. Comentários sobre a falta de investimento do governo para proporcionar o acesso dos estudantes no ambiente virtual foram expressivos. Foi apontada a falta de políticas públicas ou programas específicos e efetivos para proporcionar acesso digital dos estudantes, visto que muitos alunos não contam com recursos tecnológicos, como computadores ou tablets, e/ou não possuem pacote de dados suficiente para a realização de todas as atividades e aulas. Outro fator relevante citado pelos gestores consistiu na existência de uma falta de compreensão de alguns professores em relação a estes alunos com limitações de acesso.

Embora a organização da plataforma digital, com a institucionalização de e-mails de professores e estudantes seja considerada significativa, o processo de contratação dos dados reversos junto às operadoras de telefonia celular e o desenvolvimento de programas na grade aberta da TV, previstos para o atendimento aos estudantes, não foram viabilizados no decorrer do $1^{\text {o }}$ semestre letivo. Considerando os processos administrativos e pedagógicos de operacionalização das ações educacionais específicas para este período de pandemia, foi possível evidenciar elementos de desgaste por parte

Rev. Nova Paideia - Revista Interdisciplinar em Educação e Pesquisa Brasília/DF, v. 2, n. 2. p. 39 - 55 - $\overline{\text { ANO } 2020}$ 
dos gestores frente a situações da administração pública que superam a sua competência de atuação, mas que exercem influência direta na viabilização satisfatória dessas ações educacionais.

\subsection{Contraponto}

Em contraste com a maioria das respostas em relação ao estresse nos cargos de gestão escolar, também houve uma parcela minoritária de gestores que afirmaram não considerar o trabalho estressante. Quando questionados sobre os sintomas, dois gestores afirmaram não sentir nenhum dos apresentados no rol de opções.

Quando questionada a percepção em relação a aspectos do trabalho nos últimos sete meses (março a setembro de 2020) em comparação com o mesmo período do ano anterior, um gestor afirmou não ter percebido nenhuma mudança. Nas questões abertas foi possível identificar um posicionamento que afirmava que o trabalho pedagógico não era estressante, somente desafiador.

\section{Conclusões}

É evidente que as consequências da pandemia de COVID-19 não se reduziram a apenas aspectos biológicos, mas também impactaram questões sociais e culturais em todo o mundo. 0 efeito das demandas de isolamento e distanciamento eram imprevisíveis, visto que o vírus era desconhecido e pouco se sabia sobre seu potencial. Com a finalidade de reduzir índices de casos, houve a suspensão das aulas em todo o Brasil, e muito se foi discutido sobre o uso das tecnologias para ensino e aprendizagem como forma de reparação aos danos na área de educação. A partir disso, foi identificada uma oportunidade de estudar o impacto do coronavírus na gestão pública escolar.

Para discutir tais questões, este estudo buscou investigar se as demandas advindas da pandemia da COVID-19 intensificaram o estresse ocupacional de diretores e vice-diretores de escolas públicas de ensino médio. Para isso, foram selecionadas as escolas da região administrativa de Ceilândia, no Distrito Federal. 0 estudo contou ainda com os objetivos de identificar as demandas ocupacionais desses gestores, os principais causadores de estresse na função, e como as atividades de gestão pública escolar foram impactadas com o surgimento da pandemia.

Após a análise dos documentos citados no referencial teórico e das respostas apresentadas no questionário, foi possível identificar que existem muitos estudos sobre o estresse ocupacional de professores no setor público, porém há uma carência desse tipo de pesquisa voltado para cargos de gestão em escolas públicas. Este trabalho pode ser considerado como um progresso nesse campo de estudo e possibilita conhecer parte do cenário vivenciado por esses gestores públicos.

Foi possível identificar a preocupação dos gestores com o fato de que as questões de desigualdade social possuem um peso significativo em relação ao desempenho escolar, e o contexto de pandemia acentuou essas diferenças. Quanto às políticas de acesso digital dos estudantes, foram anunciadas recentemente pela Secretaria de Educação a viabilização do acesso aos dados reversos por meio de parceria com a Universidade de Brasília e a negociação com as operadoras de telefonia Claro e Tim. Um

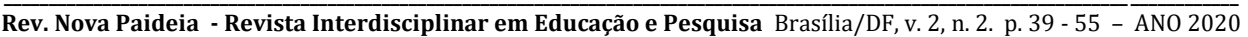


passo importante, porém, faz-se necessário o desenvolvimento de ações de promoção de inclusão digital dos estudantes e professores através do planejamento de ações de curto, médio e longo prazos no sentido de minimizar as diferenças sócio educacionais, já conhecidas anteriormente, porém explicitadas exponencialmente no cenário da pandemia.

A situação descrita pelos gestores aponta para a necessidade de ampliação dos espaços de escuta de demandas e participação dos gestores nos encaminhamentos administrativos e pedagógicos a serem aplicados nas escolas, uma vez que a operacionalização destes encaminhamentos é executada por este grupo administrativo.

Embora o estudo tenha sido voltado ao estresse em cargos de gestão pública, especialmente a gestão escolar, além das discussões sobre o tema, também foi possível identificar, pelas respostas produzidas pelos gestores, outros indicadores que podem virar estudos importantes para pesquisas futuras sobre o tema, em especial a inclusão digital de toda a comunidade escolar.

\section{REFERÊNCIAS}

BARDIN, L. Análise de conteúdo. Lisboa: Edições 70, Lisboa, 1977.

BRASIL. Constituição (1988). Constituição da República Federativa do Brasil. Brasília, DF: Senado, 1988.

BRASIL. Lei no 9394, de 20 de dezembro de 1996. Lei de Diretrizes e Bases da Educação Nacional. Brasília, DF, 20 dez. 1996.

CARLOTTO, M. S. Síndrome de Burnout em Professores: Prevalência e Fatores Associados. Psicologia: Teoria e Pesquisa, v. 27, n. 4, p. 403-410, 13 dez. 2011.

COUTO, Hudson de Araújo; VIEIRA, Fernando Luiz Herkenhoff; LIMA, Eliudem Galvão. Estresse ocupacional e hipertensão arterial sistêmica. Rev Bras Hipertens. 14(2): 112$115,2007$.

CHAKRAVARTHY, Balagi S.; WHITE, Roderik E. Stragegy process: forming, implementing and changing strategies. Londres: Sage, 2006.

CRESWELL, John W. Projeto de pesquisa: métodos qualitativo, quantitativo e misto. 2. ed. Porto Alegre: Bookman, 2010.

DISTRITO FEDERAL. Decreto $\mathrm{n}$ - 40.520 , de 14 de março de 2020. Diário Oficial do Distrito Federal. Poder Executivo, Brasília, DF, 14 mar. 2020. 28. ed.

DISTRITO FEDERAL. Lei no 4.751, de fevereiro de 2012. Diário Oficial do Distrito Federal. Poder Executivo, Brasília, DF, 07 fev. 2019. 
DISTRITO FEDERAL. Portaria no 133, de 03 de junho de 2020. Diário Oficial do Distrito Federal. Poder Executivo, Brasília, DF, 04 jun. 2020. n. 105.

DISTRITO FEDERAL. Resolução no 01, de setembro de 2019. Diário Oficial do Distrito Federal. Poder Executivo, Brasília, DF, 27 set. 2019.

DISTRITO FEDERAL. Secretaria de Estado de Educação. Governo do Distrito Federal (org.). Novo Ensino Médio: a nova organização curricular do ensino médio da seedf. a nova organização curricular do ensino médio da SEEDF. 2020. Disponível em: <http://www.educacao.df.gov.br/novo-ensino-medio/>. Acesso em: 28 ago. 2020.

GIL, Antonio Carlos. Métodos e Técnicas de Pesquisa Social. 6. ed. São Paulo: Atlas S.A., 2008.

LIBÂNEO, José Carlos. Concepções e práticas de organização e gestão da escola: considerações introdutórias para um exame crítico da discussão atual no brasil. Revista Española de Educación Comparada: Edición monográfica: Administración y gestión de los centros escolares: panorámica internacional, Madrid, Espanha, n. 13, 2007.

LUCK, Heloísa. Gestão Educacional: uma questão paradigmática. Petrópolis: Vozes, 2007. (Série Cadernos de Gestão).

MACHADO, Márcia Cristina da Silva; MIRANDA, Josélia Barbosa; DUSI, Cristina Sayuri Côrtes Ouchi; COUTINHO, Franciane Silva. 0 trabalho e os papéis de diretores de escola à luz de um modelo de gestão: um estudo na rede pública municipal de ensino de Juiz de Fora - MG. Belo Horizonte, 2014.

MALMEGRIN, Maria Leonídia. Especialização em Gestão Pública: gestão operacional. 3. ed. Florianópolis: Departamento de Ciências da Administração/ufsc, 2014. 198 p.

MARCONI, Marina de Andrade; LAKATOS, Eva Maria;. Fundamentos de Metodologia Científica. 5. ed. São Paulo: Atlas S.A., 2003.

MEYER JR., Victor; PASCUCCI, Lucilaine; MANGOLIN, Lúcia. Gestão estratégica: um exame de práticas em universidades privadas. Revista de Administração Pública, Rio de Janeiro, v. 46, n. 1, p. 49 a 70, dez. 2012.

ORGANISATION FOR ECONOMIC CO-OPERATION AND DEVELOPMENT (OECD). Education at a Glance 2020: Country Note - Brazil. [Português]: OCDE, 2020. Disponível em: <https://read.oecd-ilibrary.org/education/education-at-a-glance2020_c9b8683b-en\#page1>. Acesso em: 12 set. 2020.

TOGNETTA, Luciene Regina Paulino; MENIN, Maria Suzana de Stefano. Pandemia: desafios para a escola e seus gestores. Youtube, 29 abr. 2020. Disponível em $<$ https://www.youtube.com/watch?v=NpFWkXAiRMQ\&t=33s>. Acesso em: 06 set. 2020. 
PALMEN, Sueli Helena de Camargo. 0 trabalho do gestor na educação infantil: concepções, cenários e práticas. 2014. 289 p.

PARO, Vitor Henrique. Administração escolar: introdução crítica. 11. ed. São Paulo: Cortez, 2002. 175 p.

REIS, Ana Lúcia Pellegrini Pessoa dos; FERNANDES, Sônia Regina Pereira; GOMES, Almiralva Ferraz. Estresse e fatores psicossociais. Psicol. cienc. prof., Brasília, v. 30, n. 4, p. 712-725, dez. 2010.

SANTOS FILHO, José Camilo dos. Democracia institucional na escola: discussão teórica. Revista de Administração Educacional, Recife, v. 1, n. 2, p. 41-101, jan./jun. 1998.

SELYE, Hans. Stress: a tensão da vida. IBRASA, São Paulo. 1959.

SINDSAÚDE DF (Distrito Federal) (org.). Em 2017, 22\% dos afastamentos no serviço público do DF foram por transtornos mentais. 2018. Disponível em: <https://sindsaude.org.br/noticias/sindsaude-df/em-2017-22-dos-afastamentos-noservico-publico-do-df-foram-por-transtornos-mentais/>. Acesso em: 08 set. 2020.

VERGARA, S. C. Projetos e relatórios de pesquisa em administração. São Paulo: Atlas, 2000.

VIEIRA, Juçara Dutra. Pesquisa Sobre Saúde Condições de Trabalho dos (das) Profissionais da Educação Básica Pública. Brasília: Confederação Nacional dos Trabalhadores em Educação, 2017. 115 p. Disponível em: $<$ https://www.cnte.org.br/images/stories/2018/relatorio_pesquisa_saude_completo.pd f>. Acesso em: 08 set. 2020.

ZILLE, Luciano Pereira. Novas perspectivas para abordagem do estresse ocupacional em gerente: estudos em organizações brasileiras de diversos setores. Belo Horizonte: CEPEAD/FACE/UFMG, Belo Horizonte 2005. (Tese de Doutorado). 